\title{
"HOMICÍDIO PIEDOSO" - O DIREITO A UMA MORTE DIGNA: ANÁLISE DA LEGALIDADE DA EUTANÁSIA FRENTE À JUNÇÃO DO DIREITO À VIDA COM O PRINCÍPIO CONSTITUCIONAL DA DIGNIDADE DA PESSOA HUMANA ${ }^{1}$
}

“HOMICÍDIO PIEDOSO” - THE RIGHT TO A DIGNIFIED DEATH: ANALYSIS OF EUTHANASIA'S LEGALITY IN FRONT OF THE COMBINATION OF THE RIGHT TO LIFE WITH THE CONSTITUTIONAL PRINCIPLE OF HUMAN DIGNITY

Ana Paula Zappellini SASSI ${ }^{2}$

ISSUE DOI: $10.21207 / 2675-0104.2019 .883$

\begin{abstract}
RESUMO
A eutanásia é um procedimento através do qual o médico, baseado na vontade do doente, põe fim à sua vida. No brasil, é considerada um atentado ao direito à vida. Tomou-se, nesta pesquisa, direção contrária à atualmente seguida no País, analisando-se a eutanásia não como instrumento utilizado para retirar a vida do ser humano, mas sim como meio de defesa da dignidade da pessoa em fim de vida, que tem a morte como efeito secundário. Diante da união do direito à vida com o princípio da dignidade humana, entendeu-se que o indivíduo em situação terminal, que sofre de maneira a considerar que sua dignidade em vida está sendo violada, tem a autonomia de decidir sobre sua morte, optando por um fim de vida rápido e sem dor.
\end{abstract}

Palavras-chave: Eutanásia. Dignidade humana. Direito à vida. Morte digna.

\footnotetext{
${ }^{1} \mathrm{O}$ presente artigo sintetiza a monografia de conclusão da pesquisa, realizada para o Programa Interno de Bolsas de Iniciação Científica (PIBIC 2018-2019) da Faculdade de Direito de Franca (FDF), Franca/SP.

${ }^{2}$ Discente da Faculdade de Direito de Franca (FDF), Franca/SP. Bolsista do Programa Interno de Bolsas de Iniciação Científica (PIBIC 2018-2019).
} 


\begin{abstract}
Euthanasia is a procedure through which the doctor, based on the patient's will, end their life. In Brazil, it is considered an affront against the right to life. On this research, it was taken an opposite direction to the one that is followed in the country by analyzing euthanasia not as an instrument to take a human being's life, but as a defense means to end of life dignity which has death as a secondary effect. Uniting the right to life and the human dignity principle, it was understood that the individual in a terminal condition, that suffers in a way to consider that their dignity is being violated, has the autonomy of deciding about their death, opting for an end of life fast and without suffering.
\end{abstract}

Keywords: Euthanasia. Human dignity. Right to life. Dignified death.

\title{
A PRERROGATIVA DE UMA MORTE COM DIGNIDADE
}

A Constituição Federal de $1988^{3}$ elenca, em seu artigo $1^{\circ}$, inciso III, a Dignidade da Pessoa Humana como fundamento da República Federativa do Brasil, obrigando, portanto, o Estado a respeitar o princípio de maneira integral, sendo, dessa maneira, vedada qualquer forma de tratamento desumano, humilhante ou degradante ao indivíduo (art. $5^{\circ}$, inc. III da CF/88).

Nesse sentido, indaga Lívia Haygert Pithan $^{4}$ não se poderia falar em um direito a morrer com dignidade decorrente do direito à vida digna, uma vez sendo o princípio da dignidade humana norma-valor que baseia a interpretação do ordenamento jurídico como um todo.

Ora, se a República Federativa do Brasil oferece à sua população garantias de condição mínima de sobrevivência e, portanto, o direito a uma vida digna, há de se entender que garantiria também a opção de uma morte com dignidade a todos os seus cidadãos, uma vez que a proteção desse valor deve abranger também os últimos momentos de vida.

Dessa maneira, surgem movimentos favoráveis à prática médica voltada a abreviar a vida de pessoas que se encontram hospitalizadas em estado terminal, sem perspectiva de sobrevivência, e que passam por agudos sofrimentos físicos e emocionais: a eutanásia.

Hodiernamente, coloca-se como principal discussão bioética frente à eutanásia a autonomia individual, uma vez que ultrapassa a

\footnotetext{
${ }^{3} \mathrm{O}$ art. $1^{\circ}$, inc. III da Carta Magna assim proclama: “A República Federativa do Brasil, formada pela união indissolúvel dos Estados e Municípios e do Distrito Federal, constitui-se em Estado Democrático de Direito e tem como fundamentos: (...) - a dignidade da pessoa humana;".

${ }^{4}$ Nas palavras da autora, "Se a dignidade humana é a norma-valor que inspira a interpretação de todo o ordenamento jurídico, cabe analisar o direito à vida juntamente com a noção de dignidade - podendose falar do direito à vida digna. Não se poderia dizer, então, que do próprio direito à vida digna deriva um direito a morrer com dignidade?"
} 
vontade do médico e deixa ao enfermo a faculdade e o arbítrio de decidir sobre o fim de sua vida. De acordo com Baptista ${ }^{5}$, Joel Feinberg sustenta que a autonomia autoriza, como uma questão de direito, que uma pessoa exija respeito de outra, sendo que, por meio do conceito de autonomia ligado ao direito, o indivíduo atinge sua identidade como ser moral, livre em suas ações e digno de respeito.

Entende-se, assim, a autonomia, como o direito que é dado ao indivíduo para demandar que as decisões que toma relativamente a si sejam respeitadas por todos os outros. Na área da saúde, especialmente em relação à eutanásia, esta autonomia é seguida no momento em que o médico suporta a pretensão do doente.

Entretanto, importante notar que esse respeito pela vontade do enfermo não significa aceitação do profissional relativamente ao procedimento, visto que este deve respeitar a autonomia do paciente respeitando, por conseguinte, sua vontade de morrer - mesmo que não vincule-se à realização do procedimento, conforme seu direito à objeção de consciência.

A objeção de consciência é um dos princípios fundamentais elencados no Código de Ética Médica ${ }^{6}$ e consiste na faculdade dada ao médico, diante de sua autonomia, de negar-se a praticar atos que vão de encontro com seus valores.

O médico tem, por conseguinte, a faculdade de invocar o princípio mencionado, encaminhando o adoentado para outro profissional, quando manifestar-se contrariamente à realização do procedimento.

Ainda, no que diz respeito à autonomia da vontade, deve-se considerar a capacidade e autodeterminação do indivíduo no instante em que faz o pedido de eutanásia. Tendo em vista que a autonomia reflete o respeito da vontade do paciente em relação à sua própria vida, deve esta voluntariedade partir do próprio enfermo, e não do médico. Ademais, necessita ela ser livre e plena, sem vícios do consentimento.

\footnotetext{
${ }^{5}$ Conforme cita a autora, "Joel Feinberg (1980), um acérrimo defensor da autonomia e liberdade civil, afirma que a autonomia permite a uma pessoa exigir respeito de outra, como uma questão de direito. «É através do conceito de autonomia e direito que obtemos o nosso sentido de identidade como pessoas morais e agentes livres, merecedores de respeito»."

${ }^{6}$ Conforme o diploma: "VII - O médico exercerá sua profissão com autonomia, não sendo obrigado a prestar serviços que contrariem os ditames de sua consciência ou a quem não deseje, excetuadas as situações de ausência de outro médico, em caso de urgência ou emergência, ou quando sua recusa possa trazer danos à saúde do paciente".
} 
Desse modo, entende-se a morte digna como a faculdade dada à pessoa - ser autônomo que, de acordo com sua autodeterminação, estando em estado terminal, sem mais perspectivas de vida, entende ter sua dignidade violada a partir do momento em que percebe-se em situação de dor e sofrimento que considera desnecessário - de ter sua vida findada de maneira breve e indolor, a partir do instante em que não há mais maneira de seu direito à saúde ser tutelado no sentido de que seja-lhe proporcionado bem-estar físico e mental.

\section{EUTANÁSIA: CONCEITOS}

A palavra eutanásia possui origem grega, e resulta da união das palavras $e u$ - bom e thanatos - morte. Logo, em seu significado literal, trata-se de uma "boa morte". Sua prática, consequentemente, estaria relacionada a algo positivo: uma alternativa feliz à morte lenta e dolorosa. Nessa linha de raciocínio, Nucci ${ }^{7}$ bem esclarece que, em seu sentido etimológico, o termo quer dizer "morte suave, doce, fácil e sem dor". Ainda conforme o referido autor, a prática eutanásica também é conhecida como "homicídio piedoso, homicídio médico, compassivo, caritativo ou consensual.".

Importante diferenciar a eutanásia stricto sensu de procedimentos similares, como a mistanásia, a distanásia, a ortotanásia, o suicídio assistido e a eugenia. A mistanásia é comumente denominada eutanásia social por decorrer a morte, nesse caso, de problemas estruturais da sociedade, como a falta de sistemas básicos de higiene e moradia. O termo tem origem grega e a combinação de seus vocábulos mys e thanatos significa, conforme conceitua Pessini ${ }^{8}$, morte com dor, infeliz, que ocorre em função de estruturas que não contribuem com a vida, advindas de condições precárias de habitação, falta de saneamento básico, miséria.

Por outro lado, a ortotanásia trata-se do simples ato de desligamento dos aparelhos que sustentam a vida do adoentado terminal que, sem perspectivas de vida, deseja uma morte digna que dê fim aos seus

\footnotetext{
${ }^{7}$ NUCCI, Guilherme de Souza. Código Penal Comentado. 7. ed. São Paulo: Revista dos Tribunais, 2007. 1216 p.

${ }^{8}$ No ensinamento de Pessini, é a "morte infeliz, dolorosa, miserável, decorrente da fome, de condições precárias de habitação, falta de água potável, desemprego ou condições de trabalho massacrantes, "provocada de forma lenta e sutil por sistemas e estruturas que não favorecem a vida."' apud RAMOS, 2003, p. 117.
} 
sofrimentos. É, nas palavras de Rodrigues", a "supressão de terapêutica inútil, cuja única função é o prolongamento de sofrimentos". Sua prática não é proibida em âmbito nacional, conforme prevê o Código de Ética Médica $^{10}$ ao elencar os princípios fundamentais da medicina, proclamando que, nos casos terminais, o médico deverá evitar a realização de procedimentos desnecessários, disponibilizando aos pacientes os cuidados paliativos adequados.

Não obstante, dispõe o artigo 41, parágrafo único do referido texto legal ${ }^{11}$ que, nestas situações, o profissional deverá fornecer todos os cuidados paliativos possíveis sem efetuar "ações diagnósticas ou terapêuticas inúteis ou obstinadas", tendo sempre em conta a vontade expressa do paciente ou de seu representante legal.

Conclui-se, por conseguinte, que pode, no País, a ortotanásia ser praticada pelo profissional da medicina, desde que com o consentimento do paciente detentor de enfermidade incurável em estado terminal, ou de seu representante legal, caso o primeiro não possua condições para autodeterminar-se.

Diferentemente, o suicídio assistido, comumente denominado auxílio ao suicídio ou morte assistida, é uma espécie de eutanásia lato sensu, em que o médico, através de uma ação, ajuda o paciente a tirar a própria vida. O procedimento não tem como objetivo primordial trazer a morte, mas sim poupar o doente de dores que ele considera desnecessárias, uma vez que o fim de sua vida, devido à terminalidade da doença ou condição médica em que se encontra, é iminente.

A distanásia, como bem endossa Faria ${ }^{12}$, é a mera persistência da terapêutica médica, que tem por finalidade apenas retardar a morte, em favor da quantidade de vida e em prejuízo da vida qualitativa. Trata-se,

\footnotetext{
${ }^{9}$ apud RAMOS, 2003, p. 113.

${ }^{10}$ O princípio XXII destaca que: "Nas situações clínicas irreversíveis e terminais, o médico evitará a realização de procedimentos diagnósticos e terapêuticos desnecessários e propiciará aos pacientes sob sua atenção todos os cuidados paliativos apropriados".

${ }^{11}$ Assim prevê o Parágrafo único do princípio XXII do Código de Ética Médica: "Nos casos de doença incurável e terminal, deve o médico oferecer todos os cuidados paliativos disponíveis sem empreender ações diagnósticas ou terapêuticas inúteis ou obstinadas, levando sempre em consideração a vontade expressa do paciente ou, na sua impossibilidade, a de seu representante legal".

12 Segundo o autor: "podemos ser curados de uma doença classificada como mortal, mas não de nossa mortalidade. Quando esquecemos isso, acabamos caindo na idolatria tecnológica e na 'absolutização' da vida biológica pura e simplesmente. Insensatamente, procuramos a cura da morte e não sabemos mais o que fazer com os pacientes que estão se aproximando do adeus à vida. É a obstinação terapêutica (distanásia) adiando o inevitável, acrescentando somente mais sofrimento e vida quantitativa, mais que qualidade de vida".
} 
assim, de caso em que a medicina, através de práticas que ensejam resguardar a vida a todo custo, extrapola os limites da cura, acabando por trazer mais sofrimento ao enfermo.

Já o termo eugenia foi criado em 1883 pelo antropólogo Francis Galton, que, de acordo com Del Cont, ${ }^{13}$ "pregava o aprimoramento da raça humana (...) e até mesmo a morte de pessoas com deficiências físicas e necessidades especiais, funcionando como um instrumento de 'higienização social'”.

A eutanásia eugênica remete a práticas nazistas - perseguição de deficientes, homossexuais, ciganos e judeus, por exemplo, com a finalidade de exterminar as consideradas raças não puras -, ações que hoje são condenadas por todos os Estados de Direito, na defesa pela igualdade dos povos. A Constituição brasileira possui como princípios basilares a isonomia e o respeito à dignidade da pessoa humana. Coloca a Carta Magna $^{14}$, a dignidade humana como fundamento do Estado, comprometendo-se a combater quaisquer tipos de discriminação:

\footnotetext{
Art. $1^{\circ}$ A República Federativa do Brasil, formada pela união indissolúvel dos Estados e Municípios e do Distrito Federal, constitui-se em Estado Democrático de Direito e tem como fundamentos: (...)

III - a dignidade da pessoa humana;

IV - promover o bem de todos, sem preconceitos de origem, raça, sexo, cor, idade e quaisquer outras formas de discriminação.
}

Ademais, prevê em seu artigo $5^{\circ}$ a isonomia do povo que forma a nação brasileira, "sem distinção de qualquer natureza, garantindo-se aos brasileiros e aos estrangeiros residentes no País a inviolabilidade do direito à vida, à liberdade, à igualdade, à segurança e à propriedade". Ainda, visando a assegurar materialmente os direitos elencados pela Carta Maior brasileira, foi criada, em 1989, a Lei $\mathrm{n}^{\circ} 7.716^{15}$ contra o racismo, que prevê, em seu primeiro artigo, que "serão punidos, na forma desta Lei, os crimes resultantes de discriminação ou preconceito de raça, cor, etnia, religião ou procedência nacional". Além disso, o Estatuto da Pessoa com Deficiência ${ }^{16}$ institui que "toda pessoa com deficiência tem direito à igualdade de

\footnotetext{
13 apud VITAL SILVA, 2016.

${ }^{14}$ Constituição Federal de 1988.

${ }^{15}$ BRASIL. Lei $\mathbf{n}^{\circ} \mathbf{7 . 7 1 6}$, de 05 de janeiro de 1989. Define os crimes resultantes de preconceito de raça ou de cor.. . D.O.U., 05 jan. 1989. Disponível em: <http://www.planalto.gov.br/ccivil_03/leis/17716.htm>. Acesso em: 29 jul. 2019.

${ }^{16}$ Lei n. 13.146/15.
} 
oportunidades com as demais pessoas e não sofrerá nenhuma espécie de discriminação."

Percebe-se, por conseguinte, que o Estado Democrático de Direito brasileiro defende e protege todos os seres humanos como um todo - em especial as pessoas portadoras de deficiência e aquelas suscetíveis a preconceitos em virtude de sua crença, etnia ou procedência nacional -, ordenando que sejam tratados como iguais. Logo, deve a eugenia ser veemente rechaçada, uma vez que viola princípios constitucionais que são a base do Estado de democracia que é o Brasil, como a dignidade da pessoa humana e a isonomia, normas estas que necessitam ser amplamente respeitadas para que o bem-estar social seja promovido.

\section{O HOMICÍDIO PIEDOSO NO DIREITO BRASILEIRO}

Fazendo-se uma análise histórica da legislação brasileira, vê-se que, no Brasil, a Eutanásia nunca foi especificamente tipificada como crime, tampouco legalmente permitida, visto que sua prática é comumente associada ao homicídio privilegiado.

No artigo 198 do Código Criminal de $1830^{17}$, primeira codificação penal brasileira, havia o crime de auxílio ao suicídio: “ajudar alguém a suicidar-se, fornecer-lhe meios para esse fim com conhecimento de causa: pena de prisão, de dois a seis anos". Tal tipificação não punia a Eutanásia stricto sensu, mas sim o suicídio assistido, que se traduz no auxílio de uma pessoa na prática de suicídio de outra.

Posteriormente, com a criação do Código Penal de $1890^{18}$, passou o referido instituto a enquadrar-se no artigo 299, que acrescentou à tipificação o induzimento: "induzir ou ajudar alguém a suicidar-se, ou para esse fim fornecer-lhe meios com conhecimento de causa: pena de prisão celular de dois a quatro anos". Induzir uma pessoa a tal significa, conforme os ensinamentos de Cleber Masson ${ }^{19}$, colocar em sua mente a ideia do suicídio que, até então, era inexistente.

\footnotetext{
${ }^{17}$ Lei de 16 de dezembro de 1830.

${ }^{18}$ Decreto n. 847, de 11 de outubro de 1890, revogado pelo Decreto n. 11, de 1991.

${ }^{19}$ MASSON, Cleber. Direito penal esquematizado: parte especial. 9. ed. São Paulo: Método, 2016. $860 \mathrm{p}$.
} 
Hodiernamente, vigora no País o Código Penal de $1940^{20}$, diploma legal que preservou o crime adrede mencionado em seu artigo 122, todavia tornando-o mais específico:

\begin{abstract}
Induzir ou instigar alguém a suicidar-se ou prestar-lhe auxílio para que o faça: Pena - reclusão, de dois a seis anos, se o suicídio se consuma; ou reclusão, de um a três anos, se da tentativa de suicídio resulta lesão corporal de natureza grave.
\end{abstract}

Instigar, ainda segundo Masson" ${ }^{21}$, seria "reforçar o propósito suicida preexistente", ou seja, acentuar na pessoa sua vontade de suicidarse - a qual já existe.

Além do delito apontado, percebe-se, no Código Penal atual, a criação da figura do homicídio privilegiado ${ }^{22}$, que prevê diminuição de pena, de um sexto a um terço, nos casos em que o autor realiza o delito "impelido por motivo de relevante valor social ou moral, ou sob o domínio de violenta emoção, logo em seguida a injusta provocação da vítima". A Eutanásia, apesar de não expressamente criminalizada no ordenamento jurídico brasileiro, enquadra-se no tipo em questão - homicídio privilegiado - para fins de persecução penal.

Constitui motivo de diminuição de pena o fato de o agente realizar o fato típico por razões de compaixão, e a pedido do paciente. Há de se constatar que o atual enquadramento da referida prática em um tipo penal mais específico constitui, de certo modo, benefício ao autor do delito penal em relação à legislação anteriormente vigente, uma vez que, previamente à criação do tipo penal do homicídio privilegiado, poderia a prática do homicídio piedoso encaixar-se na tipificação do caput do artigo apontado, cuja pena arbitrada é de seis a vinte anos.

Desse modo, diante do privilégio, tem-se a redução da sanção penal, de um sexto a um terço da original. Logo, observa-se que a eutanásia vem sendo mais aceita na sociedade, posto que a pena para o cometimento de tal ato é reduzida em relação ao homicídio simples.

\footnotetext{
${ }^{20}$ Decreto-lei n ${ }^{\circ} 2.848$, de 7 de dezembro de 1940.

${ }^{21}$ MASSON, Cleber. Direito penal esquematizado: parte especial. 9. ed. São Paulo: Método, 2016. $860 \mathrm{p}$.

${ }^{22}$ Tipificado no artigo 121, parágrafo primeiro do Código Penal de 1940.
} 
Consta da exposição de motivos da Parte Especial do Código Penal $^{23}$, em seu item 39, a explicação de que motivo de relevante valor social ou moral significaria a razão que é aprovada pela moral prática, caso do homicídio eutanásico, no qual o motivo da realização do ato é a compaixão ante o sofrimento do enfermo.

Nota-se que o próprio Poder Legislativo, ao revelar os motivos da criação da nova espécie de tipicidade para o homicídio, confessa ser a eutanásia ação aprovada pela moral prática. Conforme o Dicionário Aurélio $^{24}$ : "mo.ral $s f$. 1.Conjunto de regras de conduta ou hábitos julgados válidos, quer universalmente, quer para grupo ou pessoa determinada". Logo, por moral prática, entender-se-ia a moral que é exercida pelos cidadãos na práxis diária, ou seja, o conjunto de regras de conduta ou hábitos exercidos cotidianamente e, portanto, julgados válidos para um grupo de pessoas, in casu, os cidadãos brasileiros.

Ora, se é o homicídio piedoso procedimento aceito pela moral social, indaga-se as razões pelas quais o mesmo ainda é considerado ilegal no direito material brasileiro, uma vez que os costumes da população deveriam reger as leis a serem seguidas por ela.

Poder-se-ia utilizar como motivo maior da criminalização da Eutanásia a ideia de que, uma vez legalizada, sua prática estaria sujeita à arbitragem de pessoas com o intuito simples de matar outras. Entretanto, é evidente que não deve o homicídio piedoso ser usado para fins alheios aos de compaixão a um enfermo incurável que sente muitas dores. Desse modo, ver-se-ia necessária a tipificação da eutanásia arbitral, não como homicídio privilegiado, mas como tipo penal específico.

Por ora, pode-se chegar à conclusão de que, se para os cidadãos brasileiros a eutanásia é considerada moral, ou seja, válida, seria então viável que à sua realização não fosse cominada sanção penal.

Dessa maneira, no ano de 1996 foi criado o projeto de lei $\mathrm{n}^{\circ}$ $125 / 96{ }^{25}$ no Senado, do qual constava a seguinte ementa: "autoriza a prática da morte sem dor nos casos em que especifica e dá outras providências". Segundo seu artigo $7^{\circ}$ :

\footnotetext{
${ }^{23}$ Decreto-lei n. 2.848/40, segundo o qual: "por 'motivo de relevante valor social ou moral', o projeto entende significar o motivo que, em si mesmo, é aprovado pela moral prática, como, por exemplo, a compaixão ante o irremediável sofrimento da vítima (caso de homicídio eutanásico)".

24 FERREIRA, Aurélio Buarque de Holanda. Míni Aurélio: O DICIONÁRIO DA LÍNGUA PORTUGUESA. 7. ed. Curitiba: Positivo, 2009. 895 p. REVISADO CONFORME Acordo Ortográfico.

${ }^{25}$ Único projeto de lei criado no País relativamente ao tema.
} 
Será permitida a morte sem dor do paciente em circunstâncias que acarretem sofrimentos físicos ou psíquicos, que, por sua natureza, intensidade e precariedade de prognóstico da evolução da doença, não justifiquem a continuidade da assistência médica destinada à conservação de sua existência.

Posteriormente, em 1998, entrou em vigor o Código de Ética médica que, após um processo de revisão e atualização, foi substituído pela Resolução $n^{\text {o }} 1931 / 09^{26}$ do Conselho Federal de Medicina que, em seu artigo 24, proclama ser proibido ao médico deixar de prover ao doente o exercício do direito de escolher, de maneira livre, sobre si mesmo e seu bem-estar.

Contudo, o artigo $41{ }^{27}$ da supracitada legislação impede o profissional da medicina de retirar a vida do paciente, mesmo que a seu pedido, ao mesmo tempo em que o parágrafo único do referido artigo prevê que, quando for o paciente portador de doença incurável e, estando este em estado terminal, ao médico obriga-se o oferecimento de "todos os cuidados paliativos disponíveis sem empreender ações diagnósticas ou terapêuticas inúteis ou obstinadas", devendo levar em conta a vontade expressa do doente ou, se for o caso, a de seu representante legal. Em outras palavras, é vedado ao médico realizar no adoentado, medidas desnecessárias destinadas ao prolongamento de sua vida, possuindo o profissional o dever de ouvir a vontade do doente ou de seu representante legal.

Porém, ao se combinar o artigo 24 com o artigo 41, parágrafo único, do Código de Ética Médica, pode-se concluir que ocorre uma contradição legal em relação ao caput do primeiro, visto que, ao passo em que o primeiro defende a autonomia do paciente, que tem o poder de decidir sobre sua vida, devendo o médico agir conforme a decisão deste sobre seu bem-estar, o segundo pró́be o profissional de abreviar a vida do doente a seu pedido.

Crê-se, desse modo, que, se o próprio código insiste em defender a livre-escolha do enfermo diante de doença terminal e incurável, impedir o profissional da saúde de realizar a eutanásia feriria o direito daquele de

\footnotetext{
${ }^{26}$ A Resolução, que aprovou o novo Código de Ética Médica, assim prevê, no artigo 24: "é vedado ao médico deixar de garantir ao paciente o exercício do direito de decidir livremente sobre sua pessoa ou seu bem-estar, bem como exercer sua autoridade para limitá-lo".

${ }^{27}$ É vedado ao médico: Art. 41. Abreviar a vida do paciente, ainda que a pedido deste ou de seu representante legal. Parágrafo único. Nos casos de doença incurável e terminal, deve o médico oferecer todos os cuidados paliativos disponíveis sem empreender ações diagnósticas ou terapêuticas inúteis ou obstinadas, levando sempre em consideração a vontade expressa do paciente ou, na sua impossibilidade, a de seu representante legal.
} 
agir conforme suas convicções, atacando também sua prerrogativa a uma morte digna.

Pode-se arguir que, defendendo-se a atitude médica de retirar a vida do paciente, estar-se-ia colocando sua autonomia individual princípio constitucional - em posição primordial relativamente ao direito à vida, garantia a qual, em uma análise de ponderação de normas constitucionais, seria em tese superior ao direito de escolher por si os meios e caminhos pelos quais pretende o enfermo trilhar.

Entretanto, não se trata o desacato da vontade do paciente, voltada à abreviação de sua vida por terceiro, apenas em violação de sua autonomia particular, mas sim na desconsideração de uma união de direitos, sejam eles, além do princípio acima mencionado, a inviolabilidade de sua honra, intimidade e vida privada ${ }^{28}$.

Ademais, viola-se também a vontade do doente terminal de ter uma morte que considere digna, o que lhe é garantido pelo ordenamento jurídico através da combinação do direito à vida com o princípio constitucional da dignidade da pessoa humana - que permeia toda a ordem jurídica brasileira.

Além do quê, não seria válido dizer que a conduta médica citada - ou seja, a eutanásia praticada por médico em doente terminal que passa por incalculáveis sofrimentos - constitui violação do direito à vida, uma vez que o paciente não deseja mais, neste caso, viver, e sim apenas morrer de forma tranquila.

Põe-se desse modo que, ao desrespeitar-se a vontade do paciente terminal, igualmente violam-se seus direitos à honra, à intimidade e à vida privada, além da sua autonomia de decidir por si só, conforme a dignidade que lhe é implícita - entre a vida e a morte - uma vez que, em uma cama de hospital, procura a dignidade não mais na forma de vida, mas sim na forma de óbito.

A eutanásia, a fim de que seja praticável no Brasil, necessita primeiramente ser reconhecida no País como um procedimento sério e alternativo aos tratamentos paliativos, que não objetiva simples violação do direito à vida, mas a proteção da dignidade humana em fim de vida, quando já não se veem alternativas e o sofrimento é visto como desnecessário pelo doente.

${ }^{28}$ Garantidas pelo inciso X do artigo $5^{\circ}$ da Constituição Federal. 
Além disso, é de suma importância que se conscientize a população relativamente à conceituação do termo eutanásia que, em seu sentido lato, engloba também a ortotanásia e outros procedimentos, entretanto, em sentido estrito, corresponde não ao desligamento dos aparelhos que sustentam a vida do enfermo, mas à ação do profissional médico que retira a vida do paciente em estado terminal.

Após clarificar o conceito e os objetivos do procedimento, vê-se indispensável a estipulação de requisitos básicos a serem seguidos para a realização da eutanásia no Brasil em lei específica, a fim de que se torne uma prática séria e em conformidade com determinações legais, respeitando a dignidade do ser humano em fim de vida, jamais confrontando-a. Dentre essas exigências, primordialmente, está a sua realização por um médico. No mais, o enfermo deve ter tido como diagnóstico doença ou situação de enfermidade incurável e terminal, e o pedido de eutanásia necessita ser realizado pelo próprio indivíduo, de modo sério e reiterado, devendo ele ter plena consciência e capacidade civil para fazê-lo.

Deve a busca pela eutanásia ser a última opção do adoentado, precisando este já ter recebido todos os tipos de cuidados paliativos disponíveis, além de ter sido corretamente informado e aconselhado sobre a situação de saúde em que se encontra e suas opções em fim de vida.

Por consequência, o caminho para despunibilização da eutanásia viria, de início, da aceitação, pelo Estado, da existência do princípio da morte digna, desdobramento da vida digna e inerente às pessoas em condição terminal que sofrem incalculavelmente e entendem que continuar a viver, adiando a morte inevitável, apenas causa-lhes mais dor, violando sua dignidade em fim de vida, e de suas implicações, quais sejam: o respeito pela dignidade humana em fim de vida e consequente consideração às escolhas do doente, conforme sua autonomia individual.

A partir daí, caberia ao Estado a correta informação da população acerca dos procedimentos existentes em fim de vida, além de sua diferenciação, e a criação de políticas públicas voltadas ao devido aconselhamento de pessoas em situação terminal, para, só então, a possibilidade da prática da eutanásia ser debatida. 


\section{CONSIDERAÇÕES FINAIS}

O homicídio piedoso tem como bases a união do princípio fundamental da dignidade humana e da prerrogativa de uma morte digna, assim considerada pelo indivíduo. Por conseguinte, uma vez entendendo o doente ter sua dignidade violada em fim de vida por conta das condições em que se encontra - doença terminal e incurável, que lhe causa sofrimento por ele considerado desnecessário -, deve-se dar a ele a faculdade de optar por uma morte com dignidade, ou seja, um fim de vida que cesse de maneira rápida e indolor o seu sofrimento, conforme sua vontade.

Para tal, defende-se a necessidade da existência de uma série de requisitos a serem seguidos a fim de que a eutanásia não fira a dignidade do ser humano no final da vida, mas sim traga a ele a morte com dignidade que deseja, sendo que a ausência de algum desses pressupostos não viabilizaria ao doente uma morte digna, logo, em sua falta, o procedimento não poderia ser realizado, pois afetaria a dignidade humana, princípio constitucional que serve de pressuposto à realização da eutanásia.

Ademais, percebe-se que não apenas o doente pode autodeterminar-se no sentido de escolher, de maneira autônoma, pedir ajuda para pôr fim em sua vida, mas também o médico tem o direito e a faculdade de invocar a objeção de consciência caso a realização do procedimento viole seus valores subjetivos, entregando o feitio da eutanásia a outro profissional igualmente qualificado.

Mai que isso, observa-se que, no Brasil, a eutanásia poderia vir a ser despenalizada, a depender de questões como a consagração do instituto não como uma forma de homicídio, mas sim como maneira de defesa da dignidade humana em fim de vida, de acordo com a autonomia dada ao indivíduo de decidir sobre a própria vida - e a própria morte.

Conclui-se, desse modo, que a realização da eutanásia no Brasil será viável a partir do momento em que o Estado consagre a morte digna como princípio a ser seguido, e elabore políticas públicas voltadas ao correto aconselhamento da população em relação às opções existentes em fim de vida, para que, então, os indivíduos tenham o direito ao homicídio piedoso, morte a pedido realizada por profissional médico em conformidade com a vontade do doente terminal.

\section{REFERÊNCIAS BIBLIOGRÁFICAS}


BAPTISTA, Bárbara Maria de Morais Machado. Autonomia do Doente: dos Fundamentos Teóricos às Diretivas Antecipadas de Vontade. 2012. 45 f. Dissertação (Mestrado) - Curso de Medicina, Ciências da Saúde, Universidade Beira Interior, Covilhã, 2012. Disponível em:

<https://ubibliorum.ubi.pt/bitstream/10400.6/1179/1/Disserta\%C3\%A7\%C3\%A3o\%20B $\%$ C3\%A1rbara\%20Baptista.pdf>. Acesso em: 12 jan. 2019.

BIZZATO, José Idelfonso. Eutanásia e responsabilidade médica. 2. ed. Leme: Led Editora de Direito, 2000.

BRASIL. Decreto n ${ }^{\circ} 847$, de 11 de outubro de 1890. Promulga o código penal. Código Penal dos Estados Unidos do Brazil. Sala das sessões do Governo Provisorio, 11 out. 1890. Revogado pelo Decreto n. 11, de 1991. Disponível em: <http://www.planalto.gov.br/ccivil_03/decreto/1851-1899/D847.htm>. Acesso em: 29 jul. 2019.

BRASIL. Lei de 16 de dezembro de 1830. Manda executar o Código Criminal. Código Criminal do Império do Brazil. Secretaria de Estado dos Negocios da Justiça, 08 jan. 1831. Disponível em: <http://www.planalto.gov.br/ccivil_03/leis/lim/LIM-16-121830.htm>. Acesso em: 29 jul. 2019.

BRASIL. Lei $\mathrm{n}^{\circ}$ 7.716, de 05 de janeiro de 1989. Define os crimes resultantes de preconceito de raça ou de cor.. . D.O.U., 05 jan. 1989. Disponível em:

<http://www.planalto.gov.br/ccivil_03/leis/17716.htm>. Acesso em: 29 jul. 2019.

BRASIL. Lei no 13.146, de 06 de julho de 2015. Institui a Lei Brasileira de Inclusão da Pessoa com Deficiência: Estatuto da Pessoa com Deficiência. D.O.U, 06 jul. 2015. Disponível em: <http://www.planalto.gov.br/ccivil_03/_ato20152018/2015/lei/113146.htm>. Acesso em: 29 jul. 2019.

BRASIL. Resolução n ${ }^{\circ}$ 1931, de 17 de setembro de 2009. Código de ética Médica. Diário oficial da união, 13 abr. 2010. Disponível em:

<https://portal.cfm.org.br/index.php?option=com_content\&view=category\&id=9\&Itemid =122>. Acesso em: 17 ago. 2019 .

FARIA, Ormard Andrade. Eutanásia: a morte com dignidade: depoimento. Florianópolis: Editora da Ufsc, 1997. 326 p.

FERREIRA, Aurélio Buarque de Holanda. Míni Aurélio: O DICIONÁRIO DA LÍNGUA PORTUGUESA. 7. ed. Curitiba: Positivo, 2009. 895 p. REVISADO CONFORME Acordo Ortográfico.

MARTINS, Marcio Sampaio Mesquita. Direito à morte digna: Eutanásia e morte assistida. In: Âmbito Jurídico, Rio Grande, XIII, n. 83, dez 2010. Disponível em: $<$ http://www.ambitojuridico.com.br/site/index.php?n_link=revista_artigos_leitura\&artigo_id=8765>. Acesso em out 2017. 
MASSON, Cleber. Direito penal esquematizado: parte especial. 9. ed. São Paulo: Método, 2016. $860 \mathrm{p}$.

NUCCI, Guilherme de Souza. Código Penal Comentado. 7. ed. São Paulo: Revista dos Tribunais, 2007. 1216 p.

PITHAN, Livia Haygert. A dignidade humana como fundamento jurídico das "ordens de não-ressuscitação". Porto Alegre: Edipucrs, 2004. 137 p.

RAMOS, Augusto César. Eutanásia: Aspectos Éticos e Jurídicos da Morte. Florianópolis: Oab/sc Editora, 2003. 180 p.

SARAIVA. Vade Mecum Saraiva. Obra coletiva de autoria da Editora Saraiva com a colaboração de Luiz Roberto Curia, Livia Céspedes e Juliana Nicoletti. 19. ed. São Paulo: Saraiva, 2015.

SILVA, Vital. Eutanásia: Perspectivas jurídicas e sociais para o debate no Brasil. Jusbrasil, Brasil. set. 2016. Disponível em: $<$ https://vitalsilva.jusbrasil.com.br/artigos/382046081/eutanasia-perspectivas-juridicas-esociais-para-o-debate-no-brasil>. Acesso em: 14 jan. 2019. 